\title{
Pronóstico Materno
}

Doctor Ariel Rodríguez-Astie.

El pronóstico de ias toxicosis guarda estrecha relación con la forma de ellas, con la asistencia médica que haya tenido el caso, $\mathrm{y}$ con la prontitud y eficacia de los recursos que se hayan empleado para tratar.

Los casos en los cuales a las manifestaciones toxémicas gravídicas se añaden otras afecciones tales como cardiopatias, lesiones renales. o lesiones hepáticas antiguas, tienen un pronóstico mucho más grave $\mathrm{y}$ con frecuencia en ellas fracasa el tratamiento médico.

En general a medida que aumenta el número de las crisis convulsivas el pronóstico es más grave, pero no hay que olvidar que en algunos casos una sola crisis convulsiva puede determinar la muerte bien sea por hemorragias cerebrales, por asistolia, o por coma irreversible. La albuminuria nos da igualmente una guía del pronóstico, pues su aumento progresivo e irreductible indica la gravedad misma de la afección, especialmente si a ella se agrega la oliguria también progresiva. La hipertensión arterial progresivamente ascendente y convergente agrava notoriamente el ponóstico tanto fetal como materno.

En los casos muy graves, creo que el tratamiento médico debe considerarse como una prueba clínica de la toxicosis y que, si a pesar de él, se agravan los sín. tomas tóxicos es necesario recurrir al tratamiento quirúrgico u obstétrico para evacuar el útero. bien sea por vía alta o por via bajá. con lo cual se suprime la causa única hasta hoy conocida de la intoxicción gravídica, que es el embarazo mismo. Este concepto se apoya en los datos estadisticos que ponen de manifiesto que la eclampsia del octavo al noveno mes corresponde al $76.86 \%$, y del séptimo al octavo mes abarcan un $18.5 \%$. Esto nos demuestra que la mayoría de los casos ocurren cuando es segura la viabilidad del feto, y por tanto la intervención le daria una mayor seguridad de supervivencia.

Por propia experiencia y por la atenta observación de las estadisticas consultadas en el Instituto, he llegado al convencimiento de que la toxicosis gravídica es quizá la más grave de las entidades de la patología obstétrica y la que más enluta las estadísticas. A esto contribuyen seguramente aparte de la gravedad propia de la enfermedad, el descuido de nuestra clintela hospitalaria que ignora el beneficio de la consulta prenatal y descuida las indicaciones y prescripciones que le da el médico. 